\title{
Instrumental colour measurement as a tool for light veal carcasses online evaluation
}

\author{
Alberto Horcada', Manuel Juárez², Antonio Molina³ ${ }^{3}$ Mercedes Valera' and Ma José \\ Beriain $^{4}$
}

'Department of Agroforestry Science, ETSIA, University of Seville, Seville, Spain, ${ }^{2}$ Lacombe Research Centre, Lacombe, Alberta, Canada, ${ }^{3}$ Department of Genetic, University of Cordoba, Cordoba, Spain, ${ }^{4}$ ETSIA, Public University of Navarra, Pamplona, Spain

\begin{abstract}
Eight-hundred and forty-five veal carcasses (535 males and 310 females) from Pirenaica breed and its crosses with Charolais and Limousin were used to compare carcass colour visual assessments $60 \mathrm{~min}$ post-mortem with the values obtained using a spectrocolorimeter (CIE Lab colour system) on the pectoralis superficialis muscle. Carcass weights ranged between 240 and $360 \mathrm{~kg}$. Visual colour was subjectively evaluated by two trained assessors. The best correlation between visual appraisal and $L^{*}$ was observed in carcasses of $300-320 \mathrm{~kg}$. A relatively strong correlation between visual appraisal and $a^{*}$ values was observed in carcasses of $280-300 \mathrm{~kg}$ of weight. However, the correlation between $b^{*}$ and visual appraisal was low. Using discriminant functions that included $L^{*}$ and $a^{*}$, the spectrocolorimeter classified correctly $60 \%$ of carcasses in the class colour assigned by the assessors. In fact, $99 \%$ of male and $96 \%$ of female carcasses were correctly assigned in the most common colour of veal carcasses in the Spanish market (»pink«, 5). These results indicate that online instrumental colour measurements on pectoralis superficialis muscle could be recommended to objectively evaluate carcass colour of commercial veal for the Spanish market.
\end{abstract}

Keywords: carcass colour, carcass veal, chromameter, CIE Lab 


\section{Introduction}

Carcass colour is an important factor to determine the price of carcasses at the abattoir. Specifically, consumers' assessment of general meat condition is based on their visual perception of meat colour. In this sense, Spanish veal is commonly slaughtered at the age of 12 months and $450 \mathrm{~kg}$ of body weight because carcasses show light colour. In the European Union, veal carcasses are classified according to sex, age, body weight, conformation (SEUROPsystem classification) and degree of fatness (EEC 1991). In addition, colour, as a determinant in pricing veal carcasses, is another important carcass quality characteristic. At the abattoir, qualified observers evaluate carcass conformation, degree of fatness and colour (Hulsegge \& Merkus 1999). Veal carcass colour may be visually determined by observation as a whole (Kuchida et al. 2001), or on an individual muscle such as the rectus abdominis (Hulsegge et al. 2001) or the pectoralis profundus (Lagoda et al. 2002). However, in Spain, colour scales are not officially regulated. Since the perception of colour is highly influenced by the observer, it is important to know the objective measurements of colour in order to avoid the subjective judgement (Van Oeckel et al. 1999, Lagoda et al. 2002).

Recently, the regulation EEC 1249/2008 (EEC 2008) has shown the need to develop automated techniques, statistical tests, to improve systems of classification of beef carcasses at the abattoir. Moreover the beef industry has become increasingly interested in implementing strategies for improving and reducing variation in carcass and meat quality (Cannell et al. 2002, Indurain et al. 2008). Carcass discoloration can result in a large monetary loss to the retailer and other segments of the industry. Specifically, commissions for meat quality labels are interested in an online instrumental method to determine the colour of veal carcasses at the abattoir, producing equivalent results to visual colour scales. Different instruments to determine colour have been tested for online measurement (Mancini \& Hunt 2005, Goñi et al. 2008). Earlier results showed that, using discriminant rules, spectrophotometry shows an acceptable accuracy for prediction of veal colour classes (Hulsegge et al. 2001). The reflectance spectrum obtained by spectrophotometry, as well as the trichromatric coordinates of $\mathrm{CIE}$ $L^{*} a^{*} b^{*}$, are fast, non-destructive, online and readily available methods to determine meat colour (Ripoll et al. 2008). Instrumental methods based in spectra of colour are able to appreciate individual $L^{*}, a^{*}, b^{*}$ coordinates, as reported by Denoyelle \& Berny (1999) and Indurain et al. (2008) in surface of veal carcases in the abattoir. Furthermore, studies on meat colour have reported a positive correlation between the $a^{*}$ index and the visual evaluation of colour by consumers (Chan et al. 1995). Klont et al. (1999) also observed a high correlation between visual and instrumental measurements of veal carcass colour and suggested that an objective instrumental veal carcass colour classification could be developed.

The aim of this work was to evaluate the effectiveness of instrumental colour measurements of the spectrophotometry technique on pectoralis superficialis muscle under online practical conditions in commercial abattoirs to determine carcass colour of standard young Spanish veal and to clarify whether it can replace visual assessment as a way of reducing costs and contribute to the development of the beef industry. 


\section{Material and methods}

\section{Animal management and sampling}

A total of 845 young veal (535 males and 310 females) of Pirenaica breed and its crosses with Charolais and Limousine were evaluated during a two-year period. Every two weeks, approximately 15-20 carcasses were collected from an official abattoir. Animals were killed at about $530 \mathrm{~kg}$ live weight and 390 days of age for males and $380 \mathrm{~kg}$ live weight and 340 days of age for females. Animals were slaughtered $12 \mathrm{~h}$ after arrival according to the official method (RD 640/2006). Prior to placing the carcasses in the cooler for ageing (60 min post-mortem, $3^{\circ} \mathrm{C}$ ), a licensed technician graded them for conformation and degree of fatness according to the SEUROP system (EEC 1991). Carcasses were classified using the SEUROP classification scales for conformation ( $S$, superior; $E$, excellent; $U$, very good; $R$, good; $O$; fair; $P$, poor) scoring from 18 for $» \mathrm{~S}+\ll$ to 1 for $» \mathrm{P}-\ll$. For the fat cover classification (1, low greasy; 2 , slight; 3 , medium; 4, high; 5 , very greasy) the score was 15 for $» 5+$ « and 1 for $» 1-«$.

After chilling for $24 \mathrm{~h}$ at $3^{\circ} \mathrm{C}$, carcasses were weighed and $\mathrm{pH}$ was measured in the longissimus dorsi pars lumborum muscle using a portable Crison pHmeter, model 507 (Crison instruments S.A., Barcelona, Spain), equipped with a penetration electrode and a temperature probe. According to the Spanish commercial system for bovine carcass classification (RD 225/2008), the carcasses were grouped by weight range as follows: $\mathrm{W}_{1^{\prime}}<240 \mathrm{~kg} ; \mathrm{W}_{2^{\prime}} 240-260 \mathrm{~kg} ; \mathrm{W}_{3^{\prime}}, 261-280 \mathrm{~kg} ; \mathrm{W}_{4^{\prime}} 281-300 \mathrm{~kg} ; \mathrm{W}_{5^{\prime}}, 301-320 \mathrm{~kg} ; \mathrm{W}_{6}, 321-340 \mathrm{~kg}$; $\mathrm{W}_{7^{\prime}}>340 \mathrm{~kg}$. Procedures were conducted according to the guidelines of the Council Directive $86 / 609 /$ EEC (1986) on the protection of animals used for experimental and other scientific purposes.

\section{Visual assessment of colour}

The pectoralis superficialis muscle colour was evaluated at $60 \mathrm{~min}$ post-mortem into different colour classes according a reference system proposed by the regulations of the Protected Geographical Indication »Ternera de Navarra-Nafarroako-Aratxea« (ECC 2004) for carcasses veal. A 15-point colour scale (ranging $1=$ pale pink to $15=$ dark red) was employed by two qualified independent assessors trained and accredited by the Government of Navarre (Spain). Then, a total of 1690 assessments (two for each carcass) were obtained.

\section{Instrumental determination of colour}

Carcass colour was instrumentally measured on the pectoralis superficialis muscle using a Minolta CM2002 spectrocolorimeter (Minolta Camera Co., Japan) $(\lambda: 400-700 \mathrm{~nm}, \Delta \lambda: 10 \mathrm{~nm}$, D65, $10^{\circ}$ ). Colour was expressed in the CIE $L^{*} a^{*} b^{*}$ colour system (CIE 1976). Values were determined in carcass on fat-free surface area of the pectoralis superficialis muscle. Three colour measurements for each animal were taken online using different instrument orientations. The measurement of carcass colour is recommended in the rectus abdominis muscle (American Meat Science Association 2001), but online accessibility at the abattoir is limited. However, the pectoralis superficialis muscle was chosen as one of the most accessible muscles on the carcass surface for online measurements at the abattoir. Furthermore, the pectoralis superficialis muscle shows an area free of fat and fascia after removal of the dressing over the skin of cattle. 


\section{Statistical analysis}

Descriptive statistical analysis was performed for all the studied traits. The reproducibility of visual assessment techniques was estimated as the probability that two appraisers produced the same appraisal for the same colour class. It was estimated as an intra-class correlation between assignments of the class colour measured by two appraisers. An analysis of variance was carried out to determine the statistical significance of the effect of sex and carcass weight on instrumental colour measurements and visual appraisal of carcasses. Furthermore, the correlation between visual appraisals with instrumental colour (variables $L^{*}, a^{*}$ and $b^{*}$ ) was calculated for different ranges of carcass weight using Pearson's correlation coefficient.

Finally, a forward stepwise discriminant analysis was carried out to estimate the degree of equivalence between the visual assessment and the instrumental measurement of colour in the carcasses classification. To carry out a cross validation analysis, the database was divided into two data sets. The first one, formed by $64 \%$ of the data set (1 084 assessments), was used to estimate the discriminant functions. The remaining $36 \%$ data set (616 assessments) was used to assess their predictive power (accuracy of the spectrocolorimeter according to the percentage of carcasses correctly assigned). Statistical analyses were performed using Statistica 7.0 for Windows (StatSoft, Inc., Tulsa, OK, USA,).

\section{Results and discussion}

Carcass characteristics of the animals included in this study are shown in Table 1. All carcasses included showed pH values between 5.3 and 5.7. Therefore, meat problems associated with aberrant colours had not been expected.

On average, carcasses weighed $288.0 \pm 1.5 \mathrm{~kg}$. The conformation score was in range 9-11 (corresponding » $\mathrm{R}+$ « and »U-« conformation class, respectively) and range 5-6 (slight greasy) in reference to fatness carcass. These values are representative of the light Spanish veal carcass market (Indurain et al. 2008). Among the carcass weight, the most common groups were in the range of $321-340 \mathrm{~kg}\left(\mathrm{~W}_{6}\right.$ group, $33.7 \%$ ), represented mainly by males and $\mathrm{W}_{1}$ (range $<240 \mathrm{~kg}, 29.1 \%$ ) included mainly females. $\mathrm{W}_{3}$ group was the least common range carcass weight $(0.9 \%)$. Characteristics of the carcasses and distribution weights are in accordance with data reported on commercial Spanish veal (Díez et al. 2006).

Table 1

Carcass characteristics of male and female Spanish veal carcasses

\begin{tabular}{lcccc}
\hline & \multicolumn{2}{c}{ Males $(\mathrm{n}=535)$} & \multicolumn{2}{c}{ Females $(\mathrm{n}=310)$} \\
& Mean & Standard error & Mean & Standard error \\
\hline Age, days & 385 & 15 & 342 & 15 \\
$\mathrm{pH}_{24 \mathrm{~h}}$ & 5.5 & 0.2 & 5.6 & 0.3 \\
Cold carcass weight, $\mathrm{kg}_{\text {Conformation }(1-18)^{*}}$ & 323.96 & 0.52 & 233.42 & 0.58 \\
Fatness $(1-15)^{* *}$ & 10.2 & 0.1 & 9.1 & 0.1 \\
& 5.3 & 0.1 & 5.6 & 0.1 \\
\hline
\end{tabular}

${ }^{*}$ Conformation score: 1 to 3 (P, poor), 4 to $6(0$, fair), 7 to 9 (R, good), 10 to 12 (U, very good), 13 to 15 (E, excellent), 16 to 18 (S, superior); ${ }^{* *}$ Carcass fatness: 1 , not greasy; 15 , very greasy 


\section{Visual assessment}

The distribution of 845 veal carcasses over 15 colour classes (mean values of the two observers) is shown in Figure 1. Only carcasses within 3 and 9 colour classes were reported. The largest number of carcasses (61.0\%) was classified in colour class 5 (pink). In Spain, carcasses with a score of $» 5$ « are highly valuable as consumers prefer light pinkish meat (Albertí et al. 2005). Similarly, Klont et al. (1999) in the Netherlands and Denoyelle \& Berny (1999) in France reported that pink is the most common colour in calve carcasses.

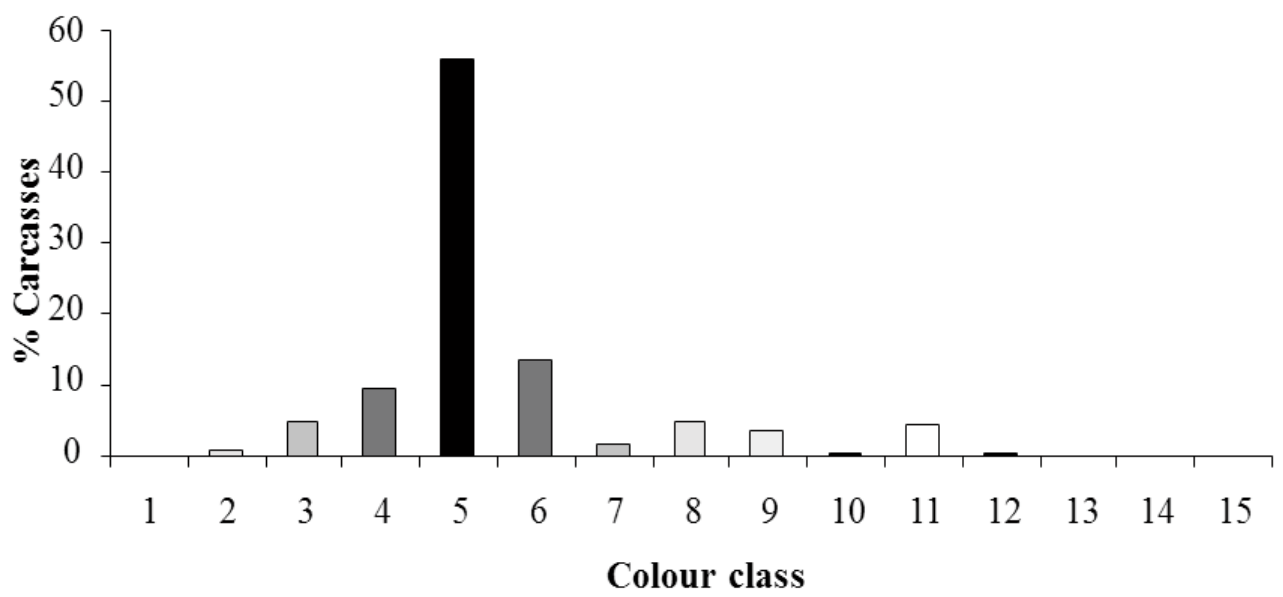

Figure 1

Distribution of visually assessed carcass colour classes (15 point colour scale: $1=$ pale pink to $15=$ dark red) of veal carcasses

Both assessors assigned $84.6 \%$ of the carcasses to the same score; in $11.4 \%$ of the carcasses there was a difference of one class. Only $4.0 \%$ of the carcasses analysed showed a difference of two classes between the values assigned by the assessors. In fact, the reproducibility of the visual colour assessment by two assessors was higher $(98 \%)$ in heavier carcasses $\left(W_{7}\right)$, with higher conformation scores $\left(U_{+}\right)$and lower degree of fatness (1+). This degree of reproducibility is higher than those described by Goñi et al. (2008) (assessor agreement $=78.0 \%$ ) and Hulsegge et al. (2001) (assessor agreement=69.4\%) using a 10 point scale. Lower agreement among assessors was reported by Eikelenboom et al. (1992) using a 5 points scale (only for $59 \%$ of the carcasses both assessors assigned the same colour class). Therefore, carrying out a study to compare the visual evaluation with instrumental colour measurements in veal carcasses is possible, as suggested by Denoyelle \& Berny (1999) and Mancini \& Hunt (2005).

\section{Relationship between colour visual and instrumental measurements}

Table 2 shows the CIE colour coordinate $\left(L^{*}, a^{*}\right.$ and $\left.b^{*}\right)$ and visual appraisal values for pectoralis superficialis muscle according to gender and carcass weight. The colour of pectoralis superficialis muscle in the present study was pink as described by Beriain et al. (2009) for 
similar animals from the Spanish market. The colour for the pectoralis superficialis muscle from females was slightly darker than for males $(P<0.01)$. Some authors have reported that dark-coloured female carcasses may be associated with higher myoglobin content (Wulf et al. 1997). Significant differences between the different carcass weights were observed $(P<0.001)$ and heavier carcasses were redder.

Table 2

Least-squares means and standard error of instrumental colour and visual appraisal of pectoralis superficialis muscle in veal carcass

\begin{tabular}{|c|c|c|c|c|c|c|c|c|}
\hline & \multicolumn{2}{|c|}{$L^{*}$} & \multicolumn{2}{|c|}{$a^{*}$} & \multicolumn{2}{|c|}{$b^{*}$} & \multicolumn{2}{|c|}{ Visual appraisal } \\
\hline & Mean & SE & Mean & SE & Mean & SE & Mean & SE \\
\hline \multicolumn{9}{|l|}{ Gender } \\
\hline Male $(n=535)$ & 46.8 & 0.2 & 3.0 & 0.1 & 2.8 & 0.2 & 5.1 & 0.1 \\
\hline \multirow[t]{2}{*}{ Female $(n=310)$} & 45.4 & 0.2 & 4.6 & 0.1 & 4.4 & 0.2 & 5.6 & 0.1 \\
\hline & \multicolumn{2}{|c|}{$* * *$} & \multicolumn{2}{|c|}{$* * *$} & \multicolumn{2}{|c|}{$* * *$} & \multicolumn{2}{|c|}{$* *$} \\
\hline \multicolumn{9}{|l|}{ Carcass weight } \\
\hline$W_{1}(n=245)$ & 47.2 & 0.2 & 2.9 & 0.1 & 2.5 & 0.2 & 5.1 & 0.1 \\
\hline$W_{2}(n=88)$ & 45.5 & 1.6 & 3.9 & 0.6 & 3.3 & 1.4 & 5.1 & 0.3 \\
\hline$W_{3}^{2}(n=8)$ & 45.9 & 0.3 & 3.2 & 0.1 & 3.6 & 0.3 & 5.1 & 0.1 \\
\hline$W_{4}^{3}(n=12)$ & 45.2 & 0.4 & 4.6 & 0.2 & 4.3 & 0.5 & 5.5 & 0.1 \\
\hline$W_{5}^{4}(n=170)$ & 45.4 & 0.3 & 4.3 & 0.2 & 4.3 & 0.4 & 5.4 & 0.1 \\
\hline$W_{6}(n=285)$ & 45.3 & 0.3 & 4.8 & 0.1 & 4.6 & 0.3 & 5.6 & 0.1 \\
\hline \multirow[t]{2}{*}{$W_{7}(n=37)$} & 45.8 & 0.6 & 4.6 & 0.4 & 4.2 & 0.9 & 6.4 & 0.5 \\
\hline & \multicolumn{2}{|c|}{$* * *$} & \multicolumn{2}{|c|}{$* * *$} & \multicolumn{2}{|c|}{$* * *$} & \multicolumn{2}{|c|}{$* * *$} \\
\hline
\end{tabular}

$\mathrm{W}_{1}:<240 \mathrm{~kg}, \mathrm{~W}_{2}: 240-260 \mathrm{~kg}, \mathrm{~W}_{3}: 261-280 \mathrm{~kg}, \mathrm{~W}_{4}: 281-300 \mathrm{~kg}_{1} \mathrm{~W}_{5}: 301-320 \mathrm{~kg}, \mathrm{~W}_{6}: 321-340 \mathrm{~kg}, \mathrm{~W}_{7}:>340 \mathrm{~kg}, 11:$ pale pink, 15: dark red. Significant differences: ${ }^{* *} P<0.001,{ }^{* *} P<0.01$

Correlation between instrumental colour values and the mean visual colour evaluation score by gender and carcass weight group are presented in Table 3. The correlation coefficients for $L^{*} a^{*}$ and $b^{*}$ values were moderate-low. The results of correlation between visual appraisal and instrumental assessment in the literature are inconsistent. In this work, correlation moderate for $L^{*}$ (range from -0.02 to -0.50 and for $a^{*}$ (range from 0.13 to 0.67 ) were observed, while the correlation coefficient for the $b^{*}$ value can be considered moderate-low (range 0.06 to -0.44). Similar results were showed by Denoyelle \& Berny (1999), who observed relatively weak correlation between the $b^{*}$ value and the visual assessment of veal carcass colour. Only Lagoda et al. (2002) found a significant correlation between the visual scores and $b^{*}$ value. The relationship between visual and instrumental colour measurements found for the $L^{*}$ and $a^{*}$ values were variable among carcass types. In the present study, the highest correlation between visual appraisal and $L^{*}$ was observed in carcasses between 301 and $320 \mathrm{~kg}\left(\mathrm{~W}_{5}\right)$ $(\mathrm{r}=-0.50 ; P<0.01)$. A relatively strong correlation was observed between visual appraisal and redness $\left(a^{*}\right)$ values in carcasses between 281 and $300 \mathrm{~kg}\left(\mathrm{~W}_{4}\right)(\mathrm{r}=0.67 ; P<0.01)$. Authors have reported a positive correlation between $a^{*}$ and the visual evaluation of colour by consumers (Chan et al. 1995). The results of this study suggest that CIE Lab coordinates in the pectoralis superficialis muscle are closely correlated with the visual colour evaluation scores, as reported by Goñi et al. (2008) in the longissimus dorsi muscle of veal. Thus, differences between $L^{*}$ and $a^{*}$ coordinates could be used to assign the colour of veal carcasses, as suggested by Denoyelle $\&$ Berny (1999), while the coordinate $b^{*}$ would not be included due to its weak 
correlation values. This use of the spectrocolorimeter would be of particular interest for determining colour of carcasses between 280 and $320 \mathrm{~kg}$.

Table 3

Correlations between $L^{*}, a^{*}, b^{*}$ in pectoralis superficialis muscle with visual appraisal from observers in veal by carcass type

\begin{tabular}{lccc}
\hline & $L^{*}$ & $a^{*}$ & $b^{*}$ \\
\hline Gender & & & \\
Males & -0.16 & 0.31 & -0.09 \\
Females & -0.03 & 0.30 & 0.26 \\
Carcass weight & & & \\
$W_{1}$ & -0.41 & 0.41 & 0.14 \\
$W_{2}$ & -0.02 & 0.25 & 0.15 \\
$W_{3}$ & -0.33 & 0.45 & 0.06 \\
$W_{4}$ & -0.19 & 0.67 & -0.39 \\
$W_{5}$ & -0.50 & 0.13 & -0.44 \\
$W_{6}$ & -0.21 & 0.18 & -0.12 \\
$W_{7}$ & -0.13 & 0.19 & -0.16 \\
\hline
\end{tabular}

$\mathrm{W}_{1}:<240 \mathrm{~kg}, \mathrm{~W}_{2}: 240-260 \mathrm{~kg}_{1} \mathrm{~W}_{3}: 261-280 \mathrm{~kg}, \mathrm{~W}_{4}: 281-300 \mathrm{~kg}, \mathrm{~W}_{5}: 301-320 \mathrm{~kg}, \mathrm{~W}_{6}: 321-340 \mathrm{~kg}, \mathrm{~W}_{7}:>340 \mathrm{~kg}$

\section{Discriminant analysis}

In order to evaluate the effectiveness of the colorimeter to determine the colour of veal carcasses compared to visual appraisal, a canonical discriminant analysis model was tested. The accuracy of each rule was assessed with the percent of correct predictions for each of the 15 colour classes. In this study, discrimination equations were developed about $64 \%$ of the assessments carcasses (684 assessments from males and 400 from females) and tested with the remaining ones (table 4). Then, under practical conditions, performance of the spectrocolorimeter was estimated in 198 male and 110 female carcasses as the percentage of carcasses correctly assigned within colour class. This percentage represented carcasses whose scores predicted by the spectrocolorimeter corresponded to the score given by visual assessment (15-point scale).

Table 4 shows the percentage of carcasses correctly assigned to their colour class by the discriminant functions using a combination of the colour coordinates values $L^{*}$ and $a^{*}$. The coordinate $b^{*}$ was not included in the model because it showed little correlation with visual assessment. In general, employing $L^{*}$ and $a^{*}$ values in classification functions, $60.8 \%$ and $59.3 \%$ of male and female carcass colour classes, respectively, were correctly assigned by the instrumental method. In fact, the spectrocolorimeter correctly classified 98.9 and $95.4 \%$ of the carcasses (male and female, respectively) within the colour class 5 . This colour class is the most common in the commercial light carcass veal in Spain (Figure 1). For other colour classes, lower correct assignations were obtained by instrumental measurement of colour. In fact, the colour classes 3, 4 and 6 could not be assigned using instrumental colour measurements. Hulssegge et al. (2001) using discriminant functions based on the instrumental colour parameter $L^{*}$ and $a^{*}$ values and 10 colour classes, reported higher percentages of correct sample classification (higher 60\%). On the other hand, Denoyelle \& Berny (1999) reported correct assignation of $80 \%$ of carcasses by instrumental colour score when a four-colour scale 
score was used. Therefore, the method proposed for colour discrimination with a 15-points scale showed difficulties and only the most frequent class in the Spanish market (5; »pink«) could be correctly assigned. This may be due to the low representation of other colour classes in the commercial veal population in Spain (sampled for the present study).

Table 4

Percentage correctly assigned to carcass veal colour based on the use of combination of $L^{*}$ and $a^{*}$ values in discriminant rules

\begin{tabular}{lccccccccc}
\hline $\begin{array}{l}\text { Colour } \\
\text { class }\end{array}$ & $\begin{array}{c}\text { Males } \\
(\mathrm{n}=198)\end{array}$ & $\begin{array}{c}\text { Females } \\
(\mathrm{n}=110)\end{array}$ & $\begin{array}{c}\mathrm{W}_{1} \\
(\mathrm{n}=73)\end{array}$ & $\begin{array}{c}\mathrm{W}_{2} \\
(\mathrm{n}=44)\end{array}$ & $\begin{array}{c}\mathrm{W}_{3} \\
(\mathrm{n}=4)\end{array}$ & $\begin{array}{c}\mathrm{W}_{4} \\
(\mathrm{n}=6)\end{array}$ & $\begin{array}{c}\mathrm{W}_{5} \\
(\mathrm{n}=740)\end{array}$ & $\begin{array}{c}\mathrm{W}_{6} \\
(\mathrm{n}=92)\end{array}$ & $\begin{array}{c}\mathrm{W}_{7} \\
(\mathrm{n}=19)\end{array}$ \\
\hline 3 & 0 & 0 & 0 & 0 & 0 & 0 & 0 & 0 & 0 \\
4 & 0 & 0 & 0 & 0 & 0 & 0 & 0 & 0 & 0 \\
5 & 98.8 & 95.4 & 93.8 & 94.6 & 97.4 & 100.0 & 100.0 & 100.0 & 98.1 \\
6 & 0 & 0 & 0 & 0 & 0 & 0 & 0 & 0 & 0 \\
7 & 0 & 14.3 & 0 & 15.4 & 0 & 0 & 0 & 0 & 0 \\
8 & 6.3 & 0 & 0 & 0 & 0 & 0 & 100.0 & 0 & 0 \\
9 & 0 & 26.9 & 0 & 27.8 & 66.7 & 0 & 0 & 0 & 0 \\
Total & 60.8 & 59.3 & 50.0 & 57.1 & 70.0 & 42.9 & 75.0 & 61.7 & 60.2 \\
\hline
\end{tabular}

$\mathrm{W}_{1}:<240 \mathrm{~kg}, \mathrm{~W}_{2}: 240-260 \mathrm{~kg}, \mathrm{~W}_{3}: 261-280 \mathrm{~kg}, \mathrm{~W}_{4}: 281-300 \mathrm{~kg}, \mathrm{~W}_{5}: 301-320 \mathrm{~kg}, \mathrm{~W}_{6}: 321-340 \mathrm{~kg}, \mathrm{~W}_{7}:>340 \mathrm{~kg}$,

Employing the discrimination function that used $L^{*}$ and $a^{*}$ coordinates on weight carcass (Table 4), the spectrocolorimeter assigned correctly the colour class for up to $50 \%$ of the carcasses (wide weight range). The discriminant function was more effective in range W5, which mainly include male carcasses. In this range of carcass weight (301 to $320 \mathrm{~kg}$ ) $75 \%$ of the carcasses were correctly assigned. Basically, the best correct assignment was observed in the visual assessment $» 5$ «. In fact, the use of discriminant function based in $L^{*}$ and $a^{*}$ coordinates was able to correctly assign $100 \%$ of the carcasses in class $» 5$ « which ranged between 281 and $340 \mathrm{~kg}$ carcass weight $\left(\mathrm{W}_{4}\right.$ to $\left.\mathrm{W}_{6}\right)$. This weight range is the most common in the Spanish veal market.

In conclusion, the evaluation of instrumental colour in the pectoralis superficialis muscle is limited. By using discriminant rules, the spectrocolorimeter shows only an acceptable accuracy for prediction of veal colour in the most common class of veal carcasses when a 15 point scale is used. The use of colour scales of less than 15 points to determine the colour of the Spanish market beef carcasses must be proposed. However, the use of a spectrocolorimeter can be recommended as an online colour determination to complete the classification systems of beef carcasses. In order to increase the accuracy of the instrumental evaluation, a wider representation of the least common carcass colour classes should be utilized.

\section{Acknowledgements}

The authors are grateful to the I.T.G. Ganadero S.A., Cooperativa del Vacuno de Navarra Soc. Coop. and »Ternera de Navarra-Nafarroako-Aratxea« Protected Geographical Indication label for their collaboration and the carcass samples used in this study. 


\section{References}

Albertí P, Ripoll G, Goyache F, Lahoz F, Olleta JL, Panea B, Sañudo C (2005) Carcass characterisation of seven Spanish beef breeds slaughtered at two commercial weights. Meat Sci 71, 514-521

American Meat Science Association (2001) Meat evaluation handbook. American Meat Science Association, Savoy, IL, USA

Beriain MJ, Goñi MV, Indurain G, Sarriés MV, Insausti K (2009). Predicting Longissimusdorsi myoglobin oxidation in aged beef based on early post-mortem colour measurements on the carcass as a colour stability index. Meat Sci 81, 439-445

Cannell RC, Belk KE, Tatum JD, Wise JW Chapman PL, Scanga JA, Smith GC (2002) Online evaluation of a commercial video image analysis system (Computer Vision System) to predict beef carcass red meat yield and for augmenting the assignment of USDA yield grades. J Anim Sci 80, 1195-1201

Chan WKM, Hakkarainen K, Faustman C, Schaefer DM, Scheller KK, Liu Q (1995) Color Stability and Microbial Growth Relationships in Beef as Affected by Endogenous a-Tocopherol. J Food Sci 60, 966-971

CIE (1976) Comision International de l'Éclairage. Official Recommendations on Uniform Colour Spaces. Colour Difference Equations and Metric Colour Terms. Suppl 2. CIE Publication 15 Colourimetry, Paris

Council Directive 86/609/EEC (1986) Council Directive of 24 November 1986 on the approximation of laws, regulations and administrative provisions of the Member States regarding the protection of animals used for experimental and other scientific purposes (86/609/EEC). Official Journal of the European Communities L 358, 1-28

Denoyelle C, Berny F (1999) Objective measurement of veal color for classification purposes. Meat Sci 53, 203-209

Díez J, del Coz JJ, Bahamonde A, Sañudo C, Olleta JL, Macie S, Campo MM, Panea B, Albertí P (2006) Identifying market segments in beef: Breed, slaughter weight and ageing time implications. Meat Sci 74, 667-675

EEC (1991) Commission Regulation (EEC) 2237/91 of 26 July 1991 amending Regulation (EEC) No 2930/81 adopting additional provisions for the application of the Community scale for the classification of carcases of adult bovine animals. Official Journal of the European Union L 204, 11-12

EEC (2004) Commission Regulation (EC) No 1483/2004 of 20 August 2004 supplementing the Annex to Regulation (EC) No 2400/96 on the entry of certain names in the Register of protected designations of origin and protected geographical indications ('Carne de la Sierra de Guadarrama', 'Ternera de Navarra' or 'Nafarroako Aratxea', 'Carne de Vacuno del País Vasco' or 'Euskal Okela', 'Ternera Asturiana' and 'Carne de (antabria'). Official Journal of the European Union L 273, 3-4

EEC (2008) Commission Regulation (EEC) No 1249/2008 of 10 December 2008 laying down detailed rules on the implementation of the Community scales for the classification of beef, pig and sheep carcases and the reporting of prices thereof. Official Journal of the European Union L 337, 3-30

Eikelenboom G, Hoving-Bolink AH, Hulsegge B (1992) Evaluation of invasive instruments for assessment of veal colour at time of classification. Meat Sci 31, 343-349

Goñi V, Indurain G, Hernández B, Beriain MJ (2008) Measuring muscle color in beef using an instrumental method versus visual color scales. J Muscle Foods 19, 209-221

Hulsegge I, Merkus GSM (1999) Development of a colour scale for colour evaluation of beef carcasses at 60 min post mortem. J Sci Food Agric 79, 907-910

Hulsegge B, Engel B, Buist W, Merkus GSM, Klont RE (2001) Instrumental colour classification of veal carcasses. Meat Sci 57, 191-195

Indurain G, Goñi V, Horcada A, Insausti K, Hernández B, Beriain MJ (2008). Colour differences among carcasses graded with similar score for conformation and fatness. Animal 2, 1093-1100

Klont RE, Barnier VMH, Smulders FJM, van Dijk A, Hoving-Bolink AH, Eikelenboom G (1999) Post-mortem variation in $\mathrm{pH}$, temperature, and colour profiles of veal carcasses in relation to breed, blood haemoglobin content, and carcass characteristics. Meat Sci 53, 195-202

Kuchida K, Hasegawa M, Suzuki M, Miyoshi S (2001) Prediction of Beef Color Standard Number from Digital Image Obtained by Using Photographing Equipment for the Cross Section of Carcass. Anim Sci J 72, 321-328 
Lagoda HL, Wilson LL, Henning WR, Flowers SL, Mills EW (2002) Subjective and objective evaluation of veal lean color. J Anim Sci 80, 1911-1916

Mancini RA, Hunt MC (2005). Current research in meat color. Meat Sci 71, 100-121

RD 640/2006, de 26 de mayo, por el que se regulan determinadas condiciones de aplicación de las disposiciones comunitarias en materia de higiene, de la producción y comercialización de los productos alimenticios. BOE 126, 19999-20002 [in Spanish]

RD 225/2008, de 15 de febrero, por el que se completa la aplicación del modelo comunitario de clasificación de las canales de vacuno pesado y se regula el registro de los precios de mercado. BOE 56, 13309-13319 [in Spanish]

Ripoll G, Joy M, Muñoz F, Albertí P (2008) Meat and fat colour as a tool to trace grass-feeding systems in light lamb production. Meat Sci 80, 239-248

StatSoft, Inc. (2006) Statistica 7. Tulsa, OK, USA

Van Oeckel MJ, Warnants N, Boucqué CV (1999) Measurement and prediction of pork colour. Meat Sci 52, 347-354

Wulf DM, O'Connor SF, Tatum JD, Smith GC (1997) Using objective measures of muscle color to predict beef longissimus tenderness. J Anim Sci 75, 684-692 